\title{
LA INDUSTRIA GUIPUZCOANA ENTRE 1930 Y 1936: \\ INCIDENCIA DE LA CRISIS ECONOMICA
}

\author{
ELENA LEGORBURU FAUS \\ Universidad de Deusto (Campus de San Sebastián)
}

Abordamos la incidencia de la crisis económica de los años treinta en una de las provincias punteras de la moderna industrialización española - pero no por ello más conocida-.

El presente trabajo efectúa un repaso detallado por las diversas especialidades que caracterizan la producción guipuzcoana, con el fin de detectar la existencia o no de dificultades y, en su caso, precisar el origen y naturaleza de éstas.

El interés del estudio reside en dos de las características de su industria: el predominio de la pequeña y mediana empresa, de modesto capital, y el mantenimiento de importantes lazos con mercados exteriores, a través de flujos de compra y venta. Ambas la sensibilizarán de forma pecualiar frente a algunas de las coordenadas de la coyuntura de los años treinta, las cuales han motivado uno de los debates más interesantes sobre la economía del siglo XX.

\section{PRESENTACION}

La crisis de 1929 y la depresión de los años posteriores constituyen uno de los fenómenos más relevantes de la economía de los países occidentales durante el período de entreguerras (1919-1939). Existen numerosos estudios sobre el grado de incidencia y características que ésta adopró en el conjunto de España. Temas como el aislamiento respecto a la coyuntura internacional, la particularidad o no del caso, el ubuen hacer" de los sucesivos ministros de Economía y Hacienda..., han venido suscitanđo polémicas ya desde el tiempo de sus protagonistas.

El nivel de conocimientos alcanzado plantea la necesidad de emprender nuevas líneas de investigación complementarias, siendo una de ellas el estudio de las variantes locales. Tal aspecto reviste gran importancia, máxime si atendemos a la peculiar estructura económica heredada de la Restauración 
borbónica (1876-1931). Esta consagró un modelo de especialización regional que se tradujo en la división del Estado en áreas dispares, tanto por su orientación productiva como por el grado de desarrollo.

Guipúzcoa fue una de las provincias que participó más activamente de la modernización económica que conduciría al País Vasco y a Cataluña a la cabecera de las zonas industrializadas de España durante el siglo XIX. Con su estudio abordamos el mundo de la pequeña y mediana empresa, protagonista de todo este proceso de consolidación fabril. Las reducidas dimensiones de los negocios constituyen un rasgo que marcará decisivamente su marcha ante las diversas circunstancias.

Con este trabajo pretendemos esbozar las coordenadas generales que enmarcaron la trayectoria entre los años 1930 y 1936. En su elaboración hemos tropezado con una falta de series estadísticas desoladora. Hemos tratado de paliar tal pobreza de datos cuantitativos con el recurso a los libros de actas, memorias, informes y artículos de prensa. Marcadas éstas en todo momento por el sesgo de los organismos que las generan - entidades patronales en su mayor parte-, han resultado muy valiosas para entender el clima en el que se desenvuelve la producción y perfilar sus problemas.

El artículo ha sido abordado desde un enfoque histórico y descriptivo, acorde con la limitación documental y naturaleza de las fuentes manejadas. Este mismo enfoque venía demandado, por otro lado, por la ausencia de trabajos referidos al tema; de ahí la panorámica detallada de los subsectores que caracterizaban a la variada producción industrial.

\section{INTRODUCCION: EL PROCESO DE INDUSTRIALIZACION GUIPUZCOANA}

El año de 1842 marca en Guipúzcoa el tránsito de una fase industrial basada en las tradicionales ferrerías, a una nueva etapa caracterizada por la modernización de sus actividades. El Decreto de Espartero de 20 de octubre de 1841 trasladaba definitivamente las históricas aduanas interiores a la línea costera y fronteriza. La consecuencia inmediata de esta medida fue la de convertir a la provincia, territorio "exento" hasta entonces, en un espacio protegido con suficiente fuerza de atracción para los inversores. Estos orientarían su capital hacia los sectores papelero y textil, frente al que había sido tradicional en los siglos anteriores, el hierro ${ }^{1}$. En junio de 1842 se inaugura la primera fábrica de papel continuo en España, "La Esperanza", en la villa de Tolosa. En torno a estas mismas fechas, la industria algodonera comienza su modernización y aparecen nuevas factorías en Vergara y Lasarte.

1 Montserrat Gárate (1976), p. 279. 
Esta serie de cambios marcaban el inicio de un proceso ascendente que quedaría consagrado en 1878 con la concesión del primer Concierto Económico. Este otorgaba a las Diputaciones vascas la facultad de percibir $y$ entregar al Tesoro una suma global encabezada - cupo- en concepto de las contribuciones de inmuebles, cultivo, ganadería, industria y comercio, cargas que correspondían a las Vascongadas tras la abolición foral - Ley de 21 de julio de $1876-$. El criterio que siguieron las instituciones provinciales para recoger la suma de los impuestos concertados consistía en el recargo de los artículos de consumo ${ }^{2}$. Un físco de estas características favoreció el coetáneo despegue industrial y comercial, garantizándole una tributación mínima.

Se puede afirmar que, desde 1890 , este proceso industrializador había arraigado definitivamente en Guipúzcoa. A los sectores pioneros - papel y textil- se les añadió la variada gama comprendida por la metalurgia - tornillería, herramienta, cerrajería, maquinaria, ferretería-, que requerían menor inversión de capital. Por otro lado, la armería tradicional abandonaba el sistema artesanal que le había caracterizado; la prosperidad que siguió a esta teconversión constituyó un incentivo para mayores inversiones.

Dos factores marcan decisivamente el desarrollo de las factorías: la ausencia de un elemento que condicione la concentración espacial de los centros fabriles, como podría haberlo sido la ubicación de riquezas naturales -materias primas, yacimientos energéticos... ${ }^{3}-$, y la modestia de su capital social - salvo unas pocas exccpciones-. La moderna industria de la provincia se había desarrollado, en su mayor parte, de modo independiente a las grandes fortunas donostiarras ${ }^{4}$.

2 La concesión de esta relativa autonomía administrativa se entiende en el marco del descontento general que se vivía en el País Vasco con motivo de la abolición foral de 21 de julio de 1876. "El Gobierno, ante la eventualidad de enfrentarse con la burguesía vasca que constituía su base social de apoyo, optó por una fórmula destinada a contentar a esta clase social sobre el requisito de asegurar sus privilegios." Luis Castells Arteche (1980), p. 22. El primer Concierto tuvo su continuación en los que se firmarían en 1887, 1894, 1906 y 1925 . 1926, sucesivamente. Sobre el control de los cargos de la Diputación por parte de la oligarquía vasca y el papel de dicha institución en el desenvolvimiento del país, véase la tesis doctoral de Luis Castells Arteche (1987).

3 Por el contrario, las posibilidades de explotación de energía eléctrica que ofrecian los rios de la provincia, de corta longitud pero fuerte pendiente, diseminarían las fábricas a lo largo de sus cuencas durate todo este proceso industrializador.

${ }_{4}$ Montserrat Gárate (1989a y b). Parece ser que la burguesía y la banca de San Sebastián optaron por orras vías de inversión, siendo éstas preferentemente comerciales. Los pequeños empresarios industriales habrían de recurrir a la reinversión de beneficios como principal fuente de acumulación de capital. Para una segunda fase, Luis Castells y Félix Luengo (1988), p. 261, añaden: "En la medida en la cual estas fábricas se expandan y tengan que hacer frente a una competencia más fuerte y con mayores niveles tecnológicos, tendrán 
A fines del siglo XIX, la mayoría de estas empresas presentan pequeñas dimensiones. Reducen costes gracias a sistemas de trabajo intensivo y a la pericia de una mano de obra cualificada, heredada de la tradición artesana comarcal; cuentan también con las modalidades del trabajo a domicilio y familiar -industria armera y yutera- y el empleo femenino - textil-. Sus orientaciones son múltiples y variadas; aprovechan al máximo las pocas materias primas disponibles y recurren a aquéllas que ofrecen mayor facilidad de importación. Estas características persistirán, en líneas generales, en las factorías de las tres primeras décadas del siglo $\mathrm{xx}$, tal y como se aprecia en la estadística elaborada por la COIG en 1931 -véase cuadro I-.

\section{CUADRO I}

Estadistica industrial de Guipúzcoa, 1931

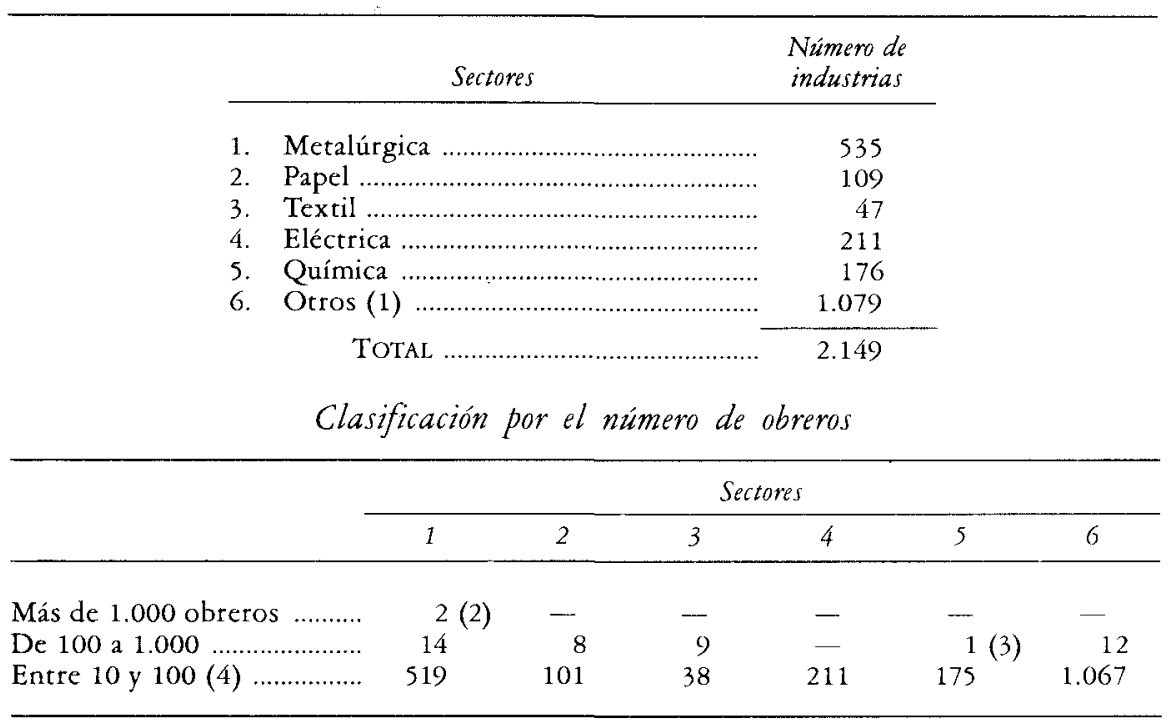

(1) Madera y muebles, alimenticias, piedras y varios.

(2) Construcción Auxiliar de Ferrocarriles (CAF) y Unión Cerrajera.

(3) Lizariturry y Rezola.

(4) Según estimación de la COIG.

Fuente: COIG. Advertencia: el recelo de los empresarios ante los requerimientos del Ministerio y la juventud de la Cámara de Industria - constituida oficialmente en 1931 - impidieron una elaboración estadística más precisa durante los años republicanos. La presente es la más detallada de las que hemos hallado.

que recurrir a capital ajeno a los socios de la empresa y adoptar formas asociativas que les permitan captar ese capital, tal como la sociedad anónima," 


\section{Estadística industrial de Guipuizcoa, 1931}

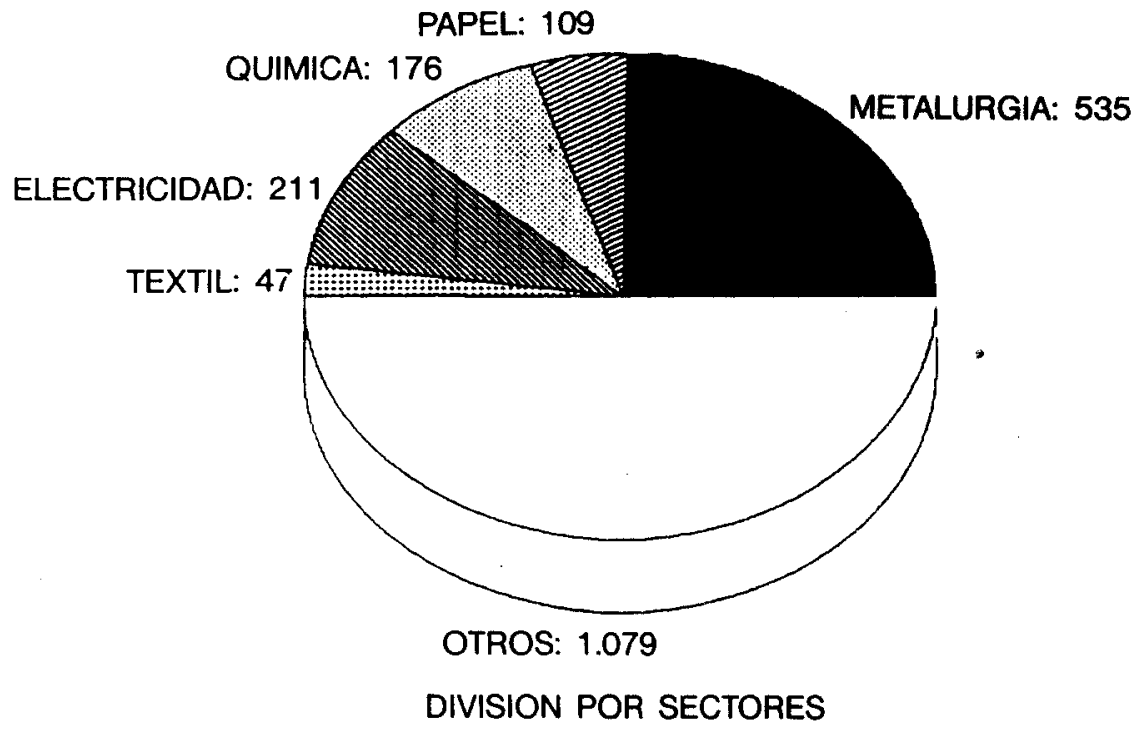

Fuente: Cuadro I.

El crecimiento de la mayoría de estos sectores precisaba un intenso tráfico de mercancías que nacía del empleo de materias primas inexistentes o deficitarias en Guipúzcoa. Su procedencia podía ser bien extranjera - madera, junco, pasta para papel, copra, yute, algodón, colorantes, goma, celuloides y materias plásticas-, bien española - pieles, madera, lana, hierro y acero-. No reviste menor importancia la demanda de una materia energética de la que carece la provincia: el carbón, de origen tanto extranjero como de diversos puntos de la cornisa cantábrica ${ }^{5}$. Entre las mercancías expedidas por la provincia figuraban el papel, el cemento y diversas manufacturas metalúrgicas y textiles que tenían mercados de ámbito nacional e incluso extranjero.

5 Sólo el amparo de una legislación proteccionista podía sostener el flujo de este suministro para la industria y la pesca, frente a la competencia del inglés. $\mathrm{L}_{2}$ imposición del consumo de carbón de la cuenca de León y Palencia acordado en 1932 por el Comité de Com. bustibles recibe el más fuerte rechazo de la industria guipuzcoana del papel, la cerámica, la química y la fundición. Los tres últimos necesitaban una variedad de "carbones gruesos» que no existía en España. No es menor el perjuicio que supone para la pesca su consumo en un 20 por 100. LGP, "Informe sobre la crisis pesquera", 1935.

6 COCIyNG, Memoria Comercial e Industrial, 1926. 


\section{LA INDUSTRIA EN LA DECADA DE LOS TREINTA}

\subsection{El metal}

La industria del hierro es una de las actividades que han caracterizado la economía vasca a lo largo de su historia, debido a la presencia de importantes yacimientos en su subsuelo que fueron detectados desde la Antigücdad. La superior calidad del mineral vizcaíno, no obstante, fue imponiéndose paulatinamente en la industria de Guipúzcoa, que recurrió a aquél en detrimento del autóctono. Esta dinámica favoreció la orientación de nuestra provincia hacia la transformación metalúrgica, actividad que se consolidó en las últimas décadas del siglo XIX, al compás de la moderna especialización siderúrgica bilbaína.

En 1930, el metal y sus derivados constituían el sector preponderante en toda la provincia. Entre sus principales ramas destacaban las de armería, construcción de vagones, ferretería y cerrajería. El mercado se extendía por toda la Península - donde los artículos guipuzcoanos habían ido logrando la sustitución de otros similares importados ${ }^{6}-$, así como por diversos países del extranjero. Se exportaban armas, baterias de cocina, herramientas..., "y mucho más se exportaría [afirmaba la COIG] si el hierro y el acero no tuvieran en España precios elevadísimos sobre los de las demás naciones»?

La evolución del sector durante los años treinta se vería afectada principalmente por dos factores: la caída de la demanda y el incremento de los costos laborales. Pasemos a su análisis.

\subsubsection{La contracción de la demanda pública y privada.}

Todos los autores están de acuerdo en la notable caída de la inversión pública en 1930 y en la incidencia que ésta tuvo en las empresas dependientes de la demanda estatal - con, toda la serie de acotaciones y matizaciones aportadas por los trabajos de F. Comín y P. Martín Aceña ${ }^{8}$-. Para el conjunto de España en 1932, se calcula un descenso de la compra de hierros destinados al ferrocarril de un 80 por 100 , y de un 60 la de los empleados en la construcción naval y edificios. Hernández Andreu señala también la

7 COIG, "Informe", 23-IV-31. Los armeros eibarreses consiguieron introducirse en los EE.UU., avalados por la reputación de sus escopetas finas de caza y pistolas automáticas de precisión. No fue ajena a este éxito la escalada de violencia que conocía aquella nación de la mano de las famosas bandas de gansters.

8 Especialmente en su artículo de 1984. 
reducción ostensible - aunque menos drástica - de la demanda particular proveniente de la agricultura e industrias diversas?.

Los datos de las principales empresas guipuzcoanas del sector - véanse cuadros II y III- confirman la tendencia estatal. Las cifras más altas de producción corresponden a los años 1929 ó 1930. A partir de estas fechas, caen hasta tocar fondo entre 1931 y 1932, en consonancia con la marcha de este mismo sector en el conjunto de España.

Un "Informe" de la COIG de 1932 enumera las empresas en crisis. Son éstas algunas de las más importantes del sector: CAF (Beasain), Compañía de Material Ferroviario (Irún), Urcola y Cía. y Múgica Hermanos (ambas de San Sebastián), entre las dedicadas al material ferroviario; José de Orueta (Rentería), Pío Larralde (Zumárraga), Aceros Lasarte y, de nuevo, CAF,

\section{CUADRO II}

Produccion de lingote de acero en Guipuizcoa (En Tm)

\begin{tabular}{|c|c|c|c|c|}
\hline \multirow[b]{2}{*}{ Años } & \multirow[b]{2}{*}{ Elgoibar } & \multicolumn{2}{|c|}{$\begin{array}{c}\text { U. Cerrajera } \\
\text { (Altos Homos de Vergara) }\end{array}$} & \multirow[b]{2}{*}{$C A F$} \\
\hline & & (1) & (2) & \\
\hline 1926 & 4.210 & 9.892 & 9.392 & 9.500 \\
\hline 1927 & 5.441 & 12.918 & 12.917 & 14.472 \\
\hline 1928 & 5.098 & 13.740 & $13.740,3$ & 9.101 \\
\hline 1929 & 7.218 & 16.711 & 16.731 & 18.762 \\
\hline 1930 & 7.252 & 18.180 & 1.628 & 19.963 \\
\hline 1931 & 4.284 & 18.828 & 16.384 & 14.769 \\
\hline 1932 & - & 14.534 & 1.450 & 3.766 \\
\hline 1933 & 4.657 & 16.059 & 17.477 & 12.725 \\
\hline 1934 & 5.838 & 18.122 & 18.121 & 14.417 \\
\hline 1935 & 3.346 & 17.707 & 17.107 & 15.433 \\
\hline 1936 & 2.326 & 13.691 & $12.741,8$ & 6.823 \\
\hline
\end{tabular}

FuENTES: CIV - para Elgoibar, CAF, Echevarría y U. Cerrajera (1)-; las Estadistica(s) Minera(s) y Metalirgica(s) para (2). Hemos incluido ambas series por las notables diferencias que mantienen para los años 1930 y 1932. Nos inclinamos, no obstante, por la credibilidad de la primera, que acusa una contracción más leve. Este comportamiento se hallaría en mayor consonancia con el hecho de que esta empresa no figure entre los nombres citados en el informe de la COIG de 1932 sobre las industrias en crisis.

\footnotetext{
9 (1979), p. 396.
} 


\section{Produción de lingote de acer en Guipúzcoa}

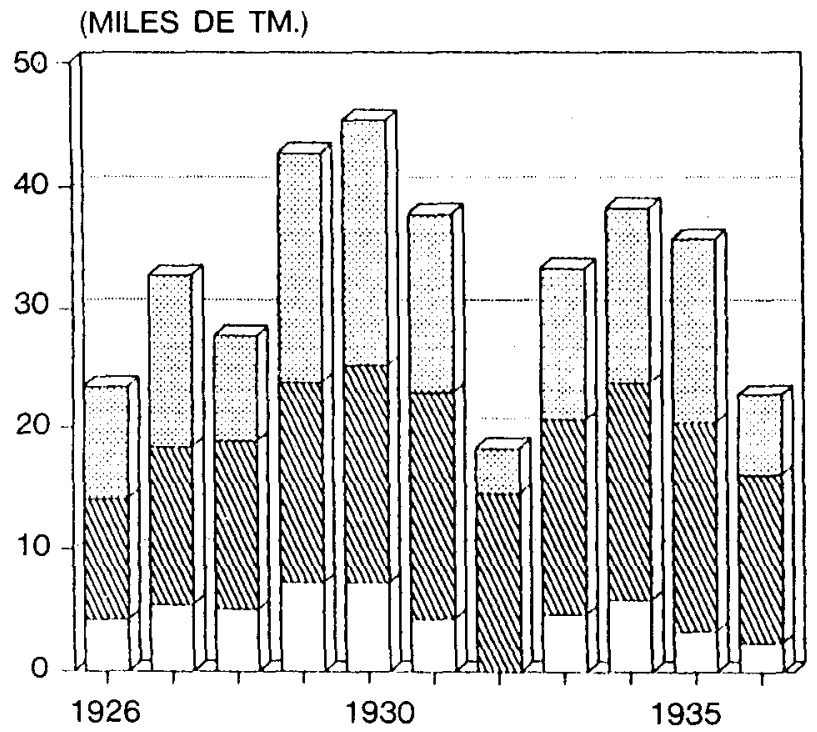

CAF

AIIIII U. CERRAJERA

$\square$ ELGOIBAR

Fuente: Cuadro II.

entre las de acero moldeado. El citado informe afirma que todas ellas ven reducida a la cuarta parte su producción normal.

La crisis se advierte con especial agudeza en la mencionada fábrica ferroviaria de Beasain, según queda recogido en la prensa local del momento. La CAF pasó de 2.200 operarios en 1931 a 754 en enero de 1934, siendo despedidos en 1932 cerca de 1.500 obreros; varios centenares de ellos, antiguos inmigrantes, fueron remitidos ese mismo año con sus familias a sus localidades de origen, previo pago del billete en tren por las autoridades locales. Esta medida se veía acompañada por la drástica reducción de la semana laboral a tan sólo tres días. A fines de 1935, la mano de obra de la fábrica no supera los 1.100 trabajadores, si bien éstos cuentan ya con una semana laboral de seis días ${ }^{\mathbf{1 0}}$.

A partir de 1933, las fuentes consultadas insisten en la persistencia de la crisis, aludiendo a un nuevo factor: el incremento de los costos laborales, de la mano de las nuevas Bases de Trabajo.

${ }^{10} E D, 13$ de febrero de 1934. 


\section{CUADRO III}

\section{Producioin de laminados en Guipuzioa \\ (En Tm)}

\begin{tabular}{|c|c|c|c|c|}
\hline \multirow[b]{2}{*}{ Años } & \multirow[b]{2}{*}{ Elgoibar. } & \multirow[b]{2}{*}{ U. Cerrajera } & \multicolumn{2}{|c|}{ Onita } \\
\hline & & & (1) & (2) \\
\hline 1926 & 3.289 & 7.898 & 992 & -.. \\
\hline 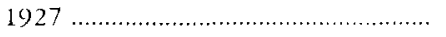 & 4.251 & 10.111 & 1.000 & -- \\
\hline 1928 & 3.984 & 10.495 & 1.100 & $\therefore$ \\
\hline 1929 & 5.693 & 12.978 & 1.032 & 150 \\
\hline 1930 & 5.666 & 14.995 & 820 & - \\
\hline 1931 & 3.792 & 10.416 & 650 & 30 \\
\hline 1932 & 2.563 & 11.330 & 300 & 1.500 \\
\hline 1933 & 3.457 & 13.015 & 380 & 800 \\
\hline 1934 & 3.862 & 12.637 & 544 & - \\
\hline 1935 & 3.409 & 13.221 & 350 & 960 \\
\hline 1936 & 1.660 & 10.742 & - & 3.110 \\
\hline
\end{tabular}

FUENTES: CIV para todas las variables, salvo la de Orueta (1), de las Estadística(s) Minera(s) y Metalírgica(s). Lo irregular y esporádico de los datos suministrados por el primero exigía su comparación con estos otros, que of recen una mayor continuidad.

\subsubsection{El aumento del coste laboral.}

El 6 de diciembre de 1932 se implantaron las nuevas bases de la siderurgia, metalurgia y derivados de Guipúzcoa ${ }^{11}$, en las que figuraban unos salarios más elevados que los de otras provincias competidoras. Como consecuencia de ello, muchas fábricas reducen la jornada laboral. En 1934, siete empresas trabajan cuarenta horas semanales, y otras 108 lo hacen treinta y dos horas.

Un nuevo Decreto, con fecha de 5 de marzo de 1936, establece la semana laboral de cuarenta y cuatro horas en el sector del metal y material eléctrico y científico, sin merma de salarios. Tal disposición afectaba al 60 por 100 de la industria guipuzcoana: a los talleres de jornada normal, por la implantación de la "semana inglesa", y a los de jornada reducida, por el 9,09 por 100 de recargo de los costes ${ }^{12}$.

11 BOG del 9 de diciembre de 1932. Estas nuevas bases eran resultado del fallo del recurso interpuesto por la patronal, que resultó ser favorable a ésta. Los nuevos salarios eran, pues, más reducidos que los anteriores.

12 COIG, "Informe al CSCC", 12 de mayo de 1936. 
Producción de laminados en Guipuizcoa

D:... ORUETA

SIIIV U. CERRAJERA

[-] ELGOIBAR

Fuente: Cuadro III.

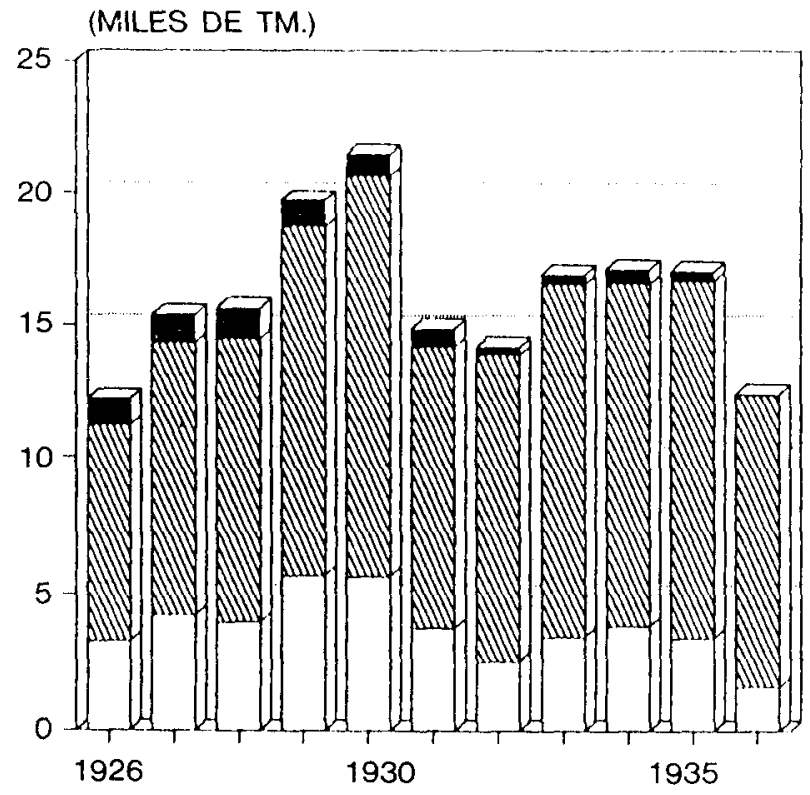

\section{CUADRO IV}

Salarios por jornada de ocho horas tomados de las Bases de Trabajo de varias industrias siderúrgicas

\begin{tabular}{|c|c|c|c|c|}
\hline \multirow[b]{2}{*}{ Categorias } & \multirow[b]{2}{*}{ Guiplizcoa } & \multirow{2}{*}{$\frac{\text { Asturias }}{\text { V1-1930 }}$} & \multicolumn{2}{|c|}{ Vizcaya } \\
\hline & & & $I V-1929$ & VIII-1933 \\
\hline Oficiales $1 .^{a} \ldots \ldots$ & 13,00 & 10,50 & 11,25 & 12,00 \\
\hline Ajustadores 2." & 12,00 & 9,35 & 10,56 & 11,00 \\
\hline Fresadores y torneros & 10,50 & - & 9,60 & 10,00 \\
\hline Peones especializados .......................... & 9,25 & 8,33 & 8,64 & - \\
\hline
\end{tabular}

Fuentes: M. Tuñón de Lara (1985), p. 286. Para Vizcaya, R. Miralles (1988a), p.120. 


\subsubsection{El caso particular de la industria armera.}

Entre las distintas especialidades metalúrgicas, la armería se distinguió por seguir una trayectoria específica.

Atravesaba ya una aguda crisis tras la contienda europea (1914-1919). Los gobiernos de diferentes Estados restringieron la circulación y venta de armas en diversos Congresos Internacionales; por otra parte, una vez finalizada la Gran Guerra, las naciones competidoras - Francia y Bélgicavolvieron a la normalidad productiva.

En lo que respecta a España, la década de los años veinte se estrenó en medio de una escalada de luchas sociopolíticas sangrientas, generadas en el ambiente de la depresión postbélica. El Gobierno decidió atajar la situación con el establecimiento de un severo control sobre la fabricación y tenencia de armas, propósito que se reflejó en el Real Decreto de 15 de noviembre de 1920 -aplicación de la Ley de 29 de abril.

Estas y otras medidas de orden público, de dudosa eficacia respecto a los fines que buscaban, acarrearían graves consecuencias para la producción, que vio resentirse la marcha de sus ventas. Tales circunstancias impulsaron a muchos de estos industriales guipuzcoanos a reorientarse hacia otras ramas metalúrgicas en los años veinte, siguiendo los pasos ya iniciados por algunas empresas locales en décadas anteriores. Nacen entonces las hojas de afeitar, los electrodomésticos, las bicicletas y las máquinas de coser de factura eibarresa - Artamendi, Solac, Orbea, BH, GAC, la cooperativa socialista Alfa-. La reconversión fue un éxito.

Entretanto, la tradicional especialidad languidecía por una dinámica legal restrictiva que incluso llegó a afectar a las escopetas de caza, ya en la II República. La gestión contra ésta y otras leyes del estilo se convertiría, de ahora en adelante, en uno de los quehaceres más premiosos de patronos y autoridades locales y provinciales. La magnitud que llega a adquirir el paro en el sector impulsará a éstas a recabar cerca de los distintos gobiernos republicanos nuevos mercados para sus armas, tanto dentro como fuera de las fronteras.

Respecto a la primera opción, en el verano de 1935, la prensa local se hace eco de la visita realizada por una Comisión de armeros eibarreses al entonces ministro de Guerra, José M. ${ }^{a}$ Gil Robles, durante su estancia en Azcoitia en esta misma época. Parece ser que éstos le ofrecieron fabricar armas con destino al ejército. La ausencia de nuevas alusiones al respecto nos revela el fracaso de la gestión.

Las miras al exterior estaban puestas sobre Letonia, Estonia, Checoslovaquia, Polonia y los países del Este europeo en general, con los que se 
quería establecer tratados comerciales que favoreciesen la exportación de $\operatorname{armas}^{13}$. Las gestiones gubernamentales, no obstante, fueron denunciadas en la prensa económica provincial como débiles y poco satisfactorias ${ }^{14}$. En 1935, el total de las armas exportadas desde la "Ciudad Ejemplar" descendió a 100.836 unidades, la cifra más baja en todo lo que había transcurrido de siglo ${ }^{15}$.

\subsection{El papel}

El papel es uno de los sectores pioneros de la moderna industrialización guipuzcoana. Arraigó en Tolosa y su comarca ya en la primera mitad del siglo XIX. Allí podía proveerse de agua abundante procedente de los caudales de los ríos de la zona - el Oria y sus afluentes-, elemènto necesario en el proceso de elaboración; disponía también de buenas comunicaciones con los principales puertos marítimos - Pasajes y San Sebastián-, que le suministraban la materia prima importada.

Las primeras fábricas se caracterizaron por la aplicación de una avanzada teconología y la concentración de la mano de obra, así como por el requerimiento de la asociación de capitales para su financiación. Pronto adquirieron tal envergadura que se situaron a la cabecera de su sector en el conjunto de la Península. El 31 de enero de 1931 asistimos a la inauguración de la fábrica más joven, la "Papelera del Oarso", de Rentería con un capital social de 6 millones de pesetas.

En 1931, Guipúzcoa era la responsable del 60 por 100 de la producción nacional de toda clase de papeles y cartones ${ }^{16}$. El grupo de mayor capacidad lo constituían los productores de papeles corrientes - de embalaje y edición-: 22 empresas, con una capacidad anual de producción de 83.320 toneladas, de las 174.220 del total español -esto es, el 47,8 por 100 .

13 La Cámara de Comercio interesa al Ministerio para que establezca un tratado comercial con Letonia, a fin de facilitar la exportación de armas. Estas se ven obligadas a pagar el 50 por 100 de recargo en los derechos arancelarios por no hallarse España convenida. Idéntica petición se repite en 1934 respecto a Estonia, donde las escopetas españolas satisfacen 15 coronas por kilogramo, frente a las siete de los países convenidos. Las dificultades respecto a Checoslovaquia son aún mayores, al no hallarse adherida al Convenio Internacional de Armas de Bruselas, de 1914.

14 J. Z. ("Juanito Zurriola"), VIP, 201, 10 de julio de 1933.

15 J. I. PAUl ARZaC, Evolución de la industria armera de Eibar, Cámara de Comercio de Guipúzcoa, San Sebastián, 1976. Citado por J. Catalán (1990).

16 COIG, Actas, 1. 
No obstante, estas cifras no cubrían el total de la demanda, por lo que se recurría a la importación del papel de prensa. En 1933, las quejas de los papeleros hallan eco en el Ministerio y consiguen que se prohíba este tráfico; pero tal medida no perdura, y el extranjero volverá a inundar el mercado nacional (véase cuadro $V)^{17}$.

\begin{tabular}{cc}
\multicolumn{3}{c}{ CUADRO V } \\
Estado comparativo \\
de importaciones de papel con \\
destino a periódicos diarios \\
\hline \\
\hline
\end{tabular}

FUENTE: Dirección General de Industria, 1935.

Los niveles de producción de este sector acusan una contracción durante la década que estudiamos; en 1934 alcanzan tan sólo el 63 por 100 de la capacidad, según cálculos de la Dirección General de Industria. Las explicaciones ofrecidas aluden a "las crecientes dificultades para comerciar con el extranjero", así como a las circunstancias concretas de algunas de las variedades: la competencia de otros países productores - principalmente Francia- con la que tropieza el papel de fumar, o eel consumo cada vez más escaso" que se observa para el de hilo" ${ }^{18}$.

17 Carta del ministro de Trabajo publicada en ED, 4 de abril de 1934.

18 Ministerio de Industria y Comercio, Dirección General de Industria (1935). 
Los informes consultados revelan otra fuente de problemas con los que se enfrentan estos industriales guipuzcoanos, y que pasamos a exponer a continuación.

\subsubsection{Conflicto con los intereses agrarios.}

El proceso de fabricación requiere pasta de madera de pinus insignis. El cultivo de esta especie comenzaba a extenderse en Guipúzcoa durante estos años, pero era aún insuficiente para cubrir la fuerte demanda. A ello se añadía la conocida pobreza española de bosques. Tales circunstancias dieron como resultado el establecimiento de estrechas relaciones comerciales con países de gran riqueza forestal, como los escandinavos. En torno a la década de los treinta se inscriben en el RM cinco compañías dedicadas al negocio de la importación de esta clase de pasta - véase cuadro VI-.. Los cua-

\section{CUADRO VI}

\begin{tabular}{ccccc}
\hline $\begin{array}{c}\text { Año de } \\
\text { registro }\end{array}$ & Razón social & $\begin{array}{c}\text { Domicilio } \\
\text { social }\end{array}$ & $\begin{array}{c}\text { Fórmula } \\
\text { societaria }\end{array}$ & $\begin{array}{c}\text { Capital } \\
\text { social } \\
\text { (ptas. })\end{array}$ \\
\hline \multirow{2}{*}{1929} & $\begin{array}{c}\text { Sociedad Española de Pastas } \\
\text { de Madera, Hansen y Cappelen }\end{array}$ & Tolosa & SA & 200.000 \\
1930 & La Hispano Finlandesa & SS & SA & 150.000 \\
1930 & Andrés Akerman y Cía., "Viking" & SS & SL & 100.000 \\
1930 & The Northern C. & Tolosa & SA & 50.000 \\
1934 & Simpler y Blidburg & Tolosa & SA & 200.000 \\
\hline
\end{tabular}

FUENTE: Libro(s) del RM de Guipúzcoa.

dros VII y VIII reflejan la marcha ascendente de este género de tráfico para el conjunto de la industria papelera española.

En el transcurso de estos años, los espartezaleros y los plantadores de alcornoques y de eucaliptus quisieron imponer su producción a esta industria, en sustitución de la pasta extranjera. La COIG denunció la política de "favorecimiento a la agricultura", que sólo podía desembocar, preveía, en la ruina de la empresa media característica de la provincia. El Decreto de 


\section{CUADRO VII}

Estado comparativo de importaciones

de pasta mecánica de madera

(Partida 1021 del Arancel)

\begin{tabular}{|c|c|c|}
\hline Años & Toneladas & $\begin{array}{c}\text { Importe } \\
\text { (miles ptas. } \\
\text { papel) }\end{array}$ \\
\hline 1925 & 17.695 & 4.777 \\
\hline 1926 & 18.304 & 4.942 \\
\hline 1927 & 18.561 & 5.382 \\
\hline 1928 & 25.236 & 8.466 \\
\hline 1929 & 28.906 & 8.685 \\
\hline 1930 & 28.872 & 10.862 \\
\hline 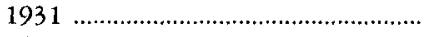 & 36.065 & 10.976 \\
\hline 1932 & 26.286 & 7.025 \\
\hline 1933 & 32.838 & 7.706 \\
\hline
\end{tabular}

FUENTE: Dirección General de Industria, 1935.

\section{CUADRO VIII}

Estado comparativo de importación de pasta quimica*

\begin{tabular}{|c|c|c|}
\hline Años & Toneladas & $\begin{array}{c}\text { Importe } \\
\text { (ptas. papel) }\end{array}$ \\
\hline 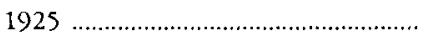 & 56.361 & 15.781 \\
\hline 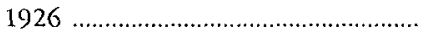 & 53.256 & 14.911 \\
\hline 1927 & 47.655 & 16.202 \\
\hline 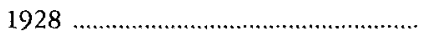 & 65.135 & 25.620 \\
\hline 1929 & 79.252 & 35.201 \\
\hline 1930 & 70.728 & 39.336 \\
\hline 1931 & 72.074 & 35.191 \\
\hline 1932 & 76.355 & 32.368 \\
\hline 1933 & 81.367 & 28.996 \\
\hline
\end{tabular}

* Celulosa.

FUENTE: Ibid. 
30 de enero de $1935^{19}$ establecía la contingentación de la pasta química de madera - celulosa-, cumpliéndose las peores previsiones de los papeleros y creando un malestar que perduraría hasta 1936. La última legislatura republicana - correspondiente al Frente Popular- no pareció mostrar intenciones de rectificar las pautas del comercio exterior.

\subsection{El textil}

En el textil guipuzcoano se distinguían varios subsectores. Los tejidos de algodón, de calidad corriente, tenían su emplazamiento en Vergara, Andoain, Oria y Rentería. Los mahones azules de la primera y las telas para sábanas y ropa de las últimas gozaban de gran aprecio en la provincia, que constituía su principal mercado. La fabricación de boinas de Azcoitia y, sobre todo, de Tolosa - «Boinas Elósegui»- era uno de los negocios más prósperos. Bajo el respaldo de una tradicional reputación, estas prendas eran consumidas en todo el territorio español y exportadas a numerosos países, constituyendo «el [producto manufacturado] que más brillante puesto ha conseguido", según comentaba la COCIyNG en 1926.

La industria yutera se circunscribía a las villas de Azcoitia y Azpeitia, que detentaban un "monopolio" de producción alpargatera, si no teórico, sí en la práctica. Su venta se extendía a las repúblicas hispanoamericanas.

Los vaivenes de la moda impulsaron, además, durante la década de los veinte, la manufactura de tejidos y géneros de punto, que comenzaba a alcanzar auge en la provincia. Los centros productores contaban con una maquinaria perfeccionada y moderna, conforme a la descripción de la ya citada Memoria.

\subsubsection{Dificultades en el abastecimiento de materia prima extranjera.}

El mismo espíritu de sustitución de importaciones que movía a los plantadores de eucaliptos animó a los algodoneros españoles respecto a las fábricas textiles. El proyecto de creación de un monopolio de venta de algodón no prosperó, para alivio de los industriales, pero diversas medidas legales entorpecieron el acceso a la materia prima extranjera.

Es en este sector donde se recoge el mayor número de quejas sobre las dificultades y extorsiones que supuso la actuación del Centro Oficial de

${ }^{19}$ Gaceta del 2 de febrero de 1935. 
Contratación de Moneda ${ }^{20}$. La canalización obligatoria de todos los cobros y pagos con el exterior a través de este organismo - "Control de Cambios" - sería utilizado por las autoridades como un sistema de contingentación encubierto que les permitía controlar las alzas o bajas de la peseta mediante el uso discrecional de las trabas burocráticas y las demoras en la concesión de divisas ${ }^{21}$. El informe de la COIG de noviembre de 1932

Puerto de Pasajes (I)

Mercancias descargadas, 1926-1934

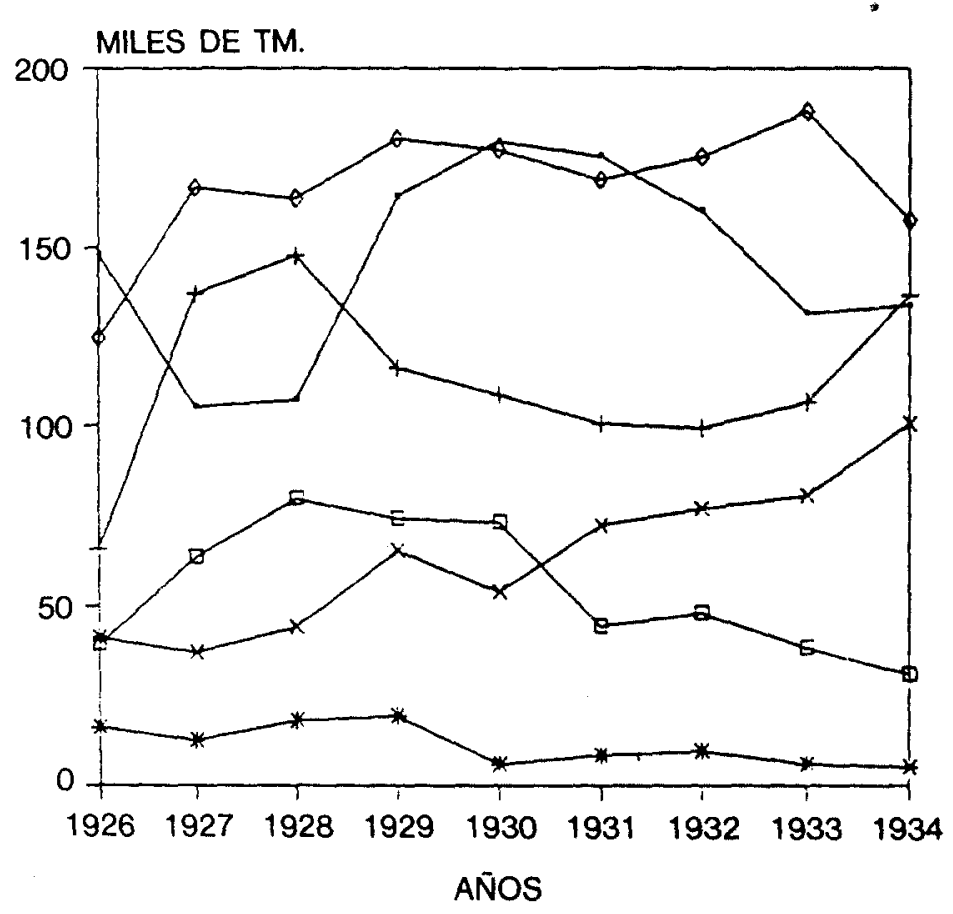

$$
\begin{aligned}
& \text { - CARBON N. + CARBON EX * MINERAL } \\
& \text { E-MADERA } \text { * PASTA MAD. - OTROS }
\end{aligned}
$$

FUENTE: COCYNG.

20 Las disposiciones de Prieto de 21 y 25 de mayo de 1931 consagraron legalmente la vigencia del control de cambios en España.

21 J. M. Serrano Sanz (1987), p. 143; R. Tamames (1981), p. 125. 
Puerto de Pasajes (II)

Mercancías cargadas, 1926-1934

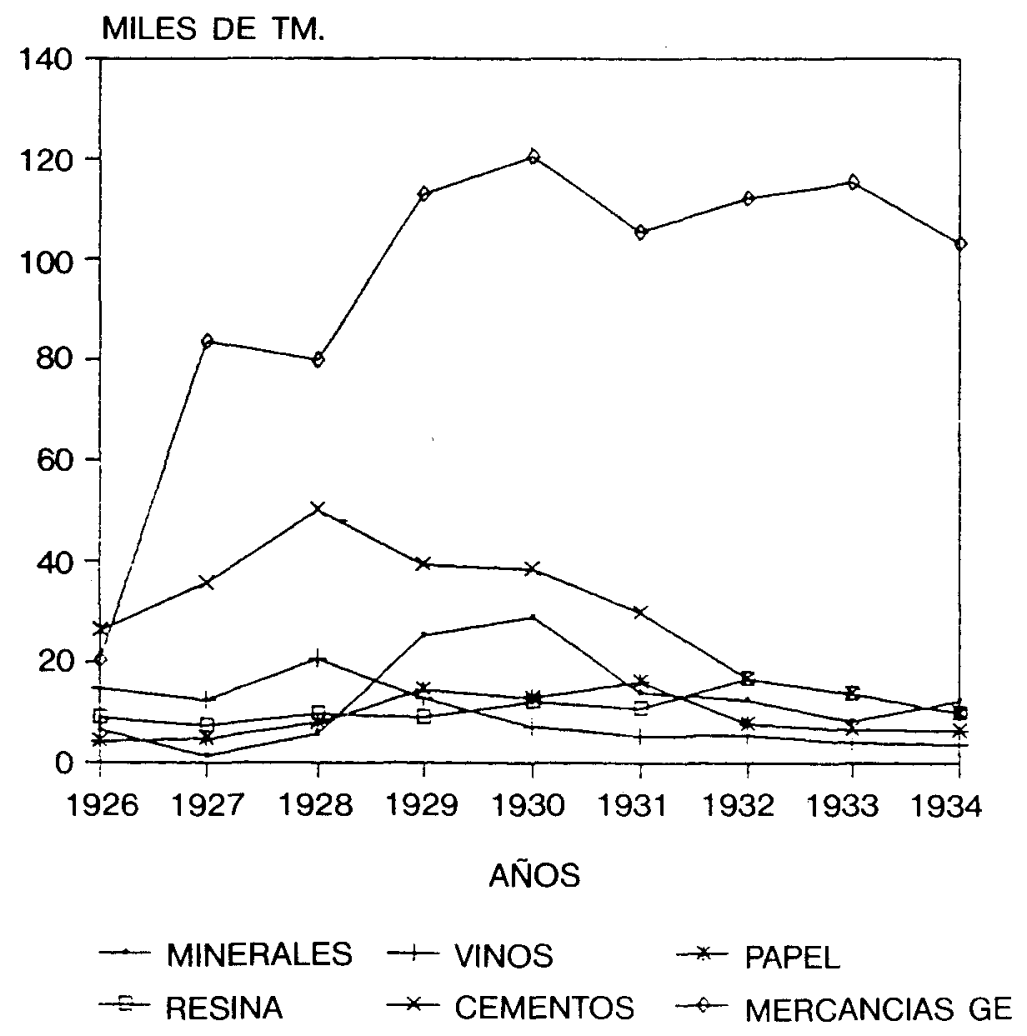

FueNTE: COCYNG.

- realizado sobre la propuesta del directivo José Manuel Brunet, dueño de una factoría textil en la localidad de Oria-Lasarte- denunciaba ya las graves consecuencias de este funcionamiento. Por un lado, ante la obligación de presentar el certificado de importación para la concesión de moneda, el vendedor extranjero no recibe el importe de su venta antes del envío; en consecuencia, cubre su riesgo con un recargo adicional en el precio. Por otro, se resienten las coberturas de créditos por importaciones ${ }^{22}$.

En 1933, las condiciones del comercio exterior se endurecen, debido a

22 Actas, 2, 1932. 
Puerto de Pasajes (III)

Movimiento general del tráfico

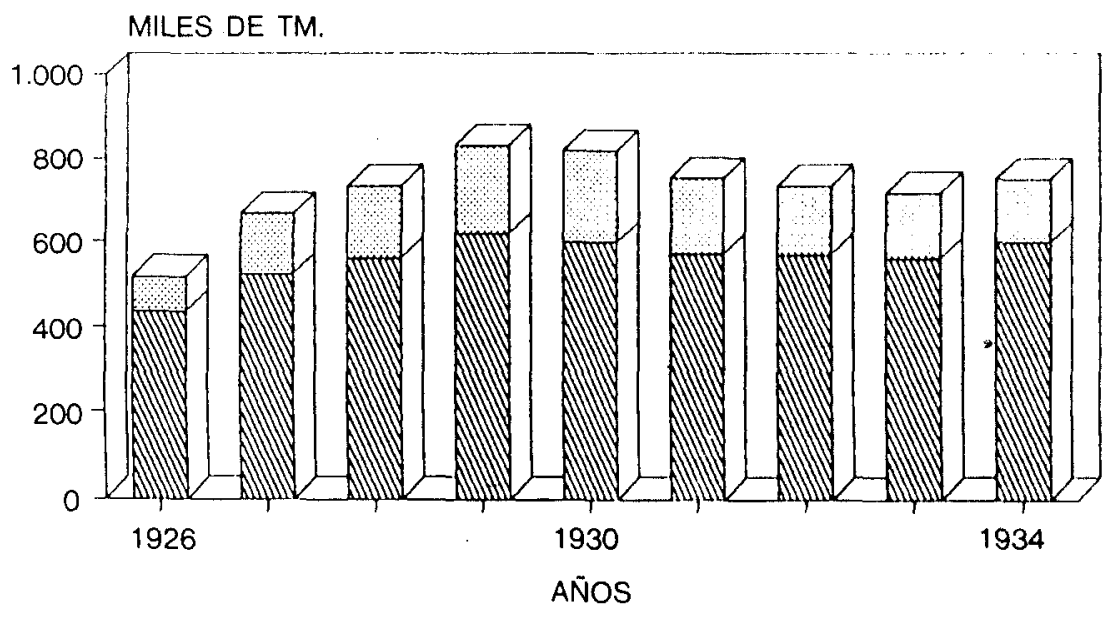

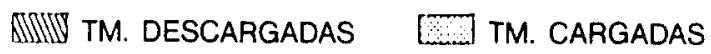

FUENTE: COCYNG.

la nueva exigencia de licencia a los importadores. La prensa económica de los dos años siguientes recoge los nombres de 197 exportadores y $666 \mathrm{im}$ portadores guipuzcoanos inscritos en los Registros correspondientes, citados en las relaciones correspondientes que publicó la Gaceta ${ }^{23}$.

Los nuevos acuerdos del Centro de Contratación no harán sino entorpecer la práctica del intercambio:

"El perjuicio [afirma la $\mathrm{COCyNG}$ ] radica siempre en lo prolongado del plazo invertido por el Centro para facilitar la moneda, que actualmente no es inferior a veinte días, y mayor aún, cuando se trata de pagos más importantes."

En 1936, la situación adquiría una mayor gravedad. Los industriales textiles $y$, en general, todos aquellos que trabajan con materias primas extranjeras debían resignarse al largo y oneroso almacenaje de éstas en puertos de transbordo o descarga. Algunas importantes factorías se hallaban a punto de cerrar por este motivo: las de los señores Zarauz, Arteche,

23 Lista publicada en la Gaceta y recogida en los núms. 631 y 632 (agosto y sepriembre de 1934) y 637 (febrero de 1935) de GE. 
Alberdi, Larrañaga y Brunet, todos ellos significados patronos ${ }^{24}$. El importe de las divisas que demandaban no alcanzaba los nueve millones de pesc$\operatorname{tas}^{25}$. Diversas entidades oficiales de la provincia gestionaban infructuosamente la apertura urgente de licencias de créditos del Centro de Contratación para el pago de dichas materias primas. La Dirección General de Aduanas denegó cualquier petición de consideración al respecto, incluída la más mínima compensación por tales quebrantos y extorsiones.

\subsubsection{La incidencia de las nuevas Bases de Trabajo.}

La legislación laboral de los años treinta afectó de lleno en un sector como el textil, en el cual era habitual recurrir al empleo femenino y al trabajo a destajo y a domicilio.

En la fabricación de boinas - Boinas Elósegui (Tolosa), Lanera Hurtado de Mendoza (Azcoitia)-- pesan las bases del Comité Paritario de 1930. Reducida la producción a menos de la mitad, los competidores de las provincias limítrofes - Navarra, Vizcaya, Burgos y Logroño-cobran impulso.

Nuevas disposiciones obligan a los industriales alpargateros a pagar las cuotas de retiro obrero y seguro de maternidad a los destajistas a domicilio, con efectos retroactivos. Las bases promulgadas en 1934 suponen, además, un aumento de jornales. La Cámara de Industria atribuye a este género de medidas la reducción de los cuarenta talleres de 1930 a los treinta y seis existentes en 1935. En el mismo intervalo de tiempo, la exportación de alpargatas desciende de 123.457 docenas a 31.445 - esto es, a su 25 por $100^{26}$.

\subsection{La quimica}

El sector químico se hallaba representado por una variada gama de manufacturas que iban desde los fármacos hasta los productos de limpieza y tocador. La mayor parte de la información recabada se ciñe a estos últimos, en función del peso que habían adquirido en el conjunto de la actividad fabril de la provincia durante las primeras décadas de este siglo. Destacaban las glicerinas - que se exportaban a Francia, Bélgica y otros países-, las estearinas, la perfumería y los jabones en la zona de la capital.

24 COIG, Actas, 2, 1936.

25 Carta de la COIG al ministro de Hacienda, 12 de mayo de 1936.

26 Memoria "Sobre el estado de la fabricación y los oficios, salarios, nacimiento y desaparición de industrias, conflictos sociales y explotaciones mineras", 10 de diciembre de 1935. 
Estos productos precisaban de aceites vegetales - copra-, grasas y sebos diversos para su elaboración, caros, deficitarios o inexistentes en España. Tal circunstancia, que generaba un tráfico de importación canalizado principalmente por el puerto de Pasajes, marcará decisivamente la naturaleza de las dificultades que sobrevengan en el transcurso de los años que estudiamos.

\subsubsection{Los problemas de los jaboneros.}

En 1931, las provincias olivareras atravesaban un difícil momento. La cosecha era una de las peores en los últimos años y las exportaciones perdían su sólida posición ante el avance del aceite italiano en el mercado mundial - véase cuadro IX - La República trajo consigo el incremento del costo de producción por la legislación social, así como una desvalorización de sus propiedades que fue propiciada por el clima en torno a la proyectada Reforma Agraria.

Los productores trataron de paliar sus pérdidas reivindicando la limitación de la competencia por medio de un refuerzo del proteccionismo y la ampliación del sistema de crédito. Llegarían a pedir la institucionalización de un monopolio del aceite o sindicación obligatoria ${ }^{27}$.

\section{CUADRO IX}

Exportación española de aceite

(En QM)

\begin{tabular}{|c|c|c|c|c|}
\hline$A \tilde{n} o s$ & $\begin{array}{l}\text { Envases de más } \\
\text { de } 20 \mathrm{Kg} .\end{array}$ & $\begin{array}{c}\text { Envases } \\
\text { pequeños }\end{array}$ & $\begin{array}{l}\text { Aceite } \\
\text { de onijo }\end{array}$ & Total \\
\hline 1928 & 864.756 & 329.097 & - & 1.193 .853 \\
\hline 1929 & 279.839 & 233.865 & - & 513.704 \\
\hline 1930 & 755.924 & 313.093 & - & 1.069 .017 \\
\hline 1931 & 651.935 & 286.651 & - & 938.586 \\
\hline 1932 & 360.415 & 269.201 & 48.610 & 678.226 \\
\hline 1933 & 267.640 & 163.792 & 19.887 & 451.319 \\
\hline
\end{tabular}

FuENTE: COIG, Actas, 21-VIII-34.

27 Mercedes Cabrera (1983), pp. 128-129. 
La industria jabonera se hallaba resentida ya desde el Decreto de 8 de junio de $1926^{28}$, encaminado a entorpecer la importación de semillas oleaginosas, sebos y grasas para usos industriales. Nuevos decretos pretenderían limitar la entrada de aceite de copra a 10.000 toneladas anuales - cuando el consumo en España, según la COIG, alcanzaba las 50.000-, y suprimir la importación de las partidas de semillas oleaginosas, aceites de palma y de coco, sebos y grasas animales sin manufacturar.

La presión de olivareros y orujeros arreciaría desde 1933, año en el que consiguieron la contingentación del aceite de copra. Le seguirían otras medidas restrictivas sobre sebos, grasas y subproductos animales y vegetales, con el mismo fin ${ }^{29} ; 1933$ es también el año en el que, ante la gravedad de la situación, comienzan a pedir que se instituya el mencionado proyecto de monopolio del aceite de sindicación obligatoria - que no prosperará-, empujados por el ejemplo italiano. Las cifras de entrada de estos productos en una de las principales factorías guipuzcoanas de jabón, Lizariturry y Rezola, de San Sebastián, son ilustrativas de la importancia que adquiría este tráfico en la marcha del sector - véase cuadro X-.

\section{CUADRO X}

Entradas de sebos y grasas en la fábrica de Lizariturry y Rezola, S. A.

\begin{tabular}{|c|c|c|c|c|}
\hline \multirow[b]{2}{*}{$A n ̃ o s$} & \multicolumn{3}{|c|}{$\begin{array}{c}\text { SEBOS } \\
\text { Partida del Arancel } 211 \\
\text { Kg. empleados en }\end{array}$} & \multirow{2}{*}{$\begin{array}{c}\text { GRASAS } \\
\text { Partida del Arancel } 212 \\
\text { Kg. empleados en }\end{array}$} \\
\hline & Estearina & Jabón & Total & \\
\hline $1924 \ldots \ldots \ldots \ldots \ldots \ldots \ldots \ldots$ & 377.570 & 368.693 & 746.263 & 887.911 \\
\hline $1925 \ldots \ldots \ldots \ldots \ldots \ldots \ldots \ldots$ & 1.026 .223 & 1.053 .705 & 2.079 .928 & 876.717 \\
\hline $1926 \ldots \ldots \ldots \ldots \ldots \ldots$ & 1.184 .318 & 544.439 & 1.728 .757 & 639.459 \\
\hline $1927 \ldots \ldots \ldots \ldots \ldots \ldots \ldots \ldots$ & 820.000 & 465.836 & 1.293 .836 & 911.094 \\
\hline (n.................... & 798.323 & 742.663 & 1.540 .986 & 1.011 .692 \\
\hline ........................ & 1.056 .010 & 998.908 & 2.054 .918 & 759.172 \\
\hline $1930 \ldots \ldots \ldots \ldots \ldots \ldots \ldots \ldots$ & 1.125 .761 & 1.066 .610 & 2.192 .371 & 1.277 .979 \\
\hline $1931 \ldots \ldots \ldots \ldots \ldots \ldots$ & 1.055 .815 & 948.513 & 2.004 .328 & 1.226 .289 \\
\hline $1932 \ldots \ldots \ldots \ldots \ldots \ldots \ldots$ & 828.000 & 904.866 & 1.732 .866 & 1.286 .591 \\
\hline
\end{tabular}

FUfNTE: Escrito elevado por la COIG al presidente del Consejo Ordenador de Economía Nacional, ante la Orden del Ministerio de Agricultura, Industria y Comercio de 28 de abril de 1933 (Gaceta del 5), que restringe la entrada de subproductos animales.

28 Gaceta del 9 de junio de 1926.

29 En Gaceta(s) de 26 de mayo, 1 y 26 de octubre de 1933 y de 17 de agosto de 1934. 
Alterada la normalidad del abastecimiento procedente del extranjero, los fabricantes guipuzcoanos no dejaron de mostrar su profundo descontento en informes, memorias, prensa económica... Al mismo tiempo, presionaban cerca del Ministerio directa o indirectamente por medio del CSCC. Estos esfuerzos fueron infructuosos. No parece ser ajena la complicidad del Parlamento y de los gobiernos republicanos del Segundo Bienio iniciado en diciembre de 1933. La nueva legislatura, de mayoría cedista y radical, no ocultaba sus simpatías a los grandes propietarios de tierras, quienes constituían uno de sus más firmes apoyos sociales. En la Asamblea General de la Liga de Productores de 1934, celebrada en el Hotel de Londres, se oían las quejas siguientes:

"Cada triunfo de los agrarios contra la química y la industria (...) produce nuevas aspiraciones de ese lamentable género y ya están procesados, para juicios sin defensa y con un rigor de persecución que ha desaparecido del Código Penal, la pasta de madera para la fabricación de papel, el sisal y el abacá que empleábamos en hilo en las gavilladoras, y el algodón cuya libre entrada permitió el desarrollo y progreso de la industria algodonera que tantos millones de pesetas rescata en su exportación competidora en todos los mercados» ${ }^{30}$.

\subsubsection{Otros subsectores quimicos.}

Las industrias que empleaban fuel-oil como primera materia sufrieron también la elevación uinmotivada y perjudicialísima" del 60 por 100 del precio por CAMPSA - de 125 a 200 pesetas la tonelada-. La Esmaltería Guipuzcoana y otras factorías de Beasain, Tolosa, Mondragón y Legazpia hallaron muchas dificultades para su normal funcionamiento por el mismo motivo. Denunciaban además que, desde dicho encarecimiento, se les suministraba tan sólo el fuel-oil de tipo corriente, combustible con un 99 por 100 de densidad, "de imposible aplicación" ${ }^{31}$.

La Guerra Civil sorprende a la Cámara de Industria cuando gestiona, en conjunción con Fomento del Trabajo Nacional, la suspensión de dos nuevos decretos sobre ordenación de producción y venta de combustibles nacionales.

\footnotetext{
30 Memoria Antual.

31 COIG, Actas, 2, 1934.
} 


\subsection{Otros sectores}

El cemento fue uno de los sectores más favorecidos por la política de obras públicas adoptada en la década anterior, bajo la Dictadura de Primo.

La producción atravesó una recesión entre los años 1930 y 1934. En esta crisis concurrían, como ha demostrado Antonio Gómez Mendoza, no sólo el giro de la política de inversión pública, sino también un problema de superproducción, que venía siendo arrastrado desde años antes ${ }^{32}$. El caso de "Cementos Rezola", una de las productoras de portland de mayor envergadura del sector a nivel nacional y la primera en Guipúzcoa, es especialmente ilustrativo para este tema (véase cuadro XI).

En 1934, ante la persistente caída de ventas y la tendencia de los precios a la baja, los fabricantes constituyen un cảrtel, COMAC - Comercial de Materiales de Construcción-. Las cifras de "La Esperanza" para 1935

\section{CUADRO XI}

Producción de cemento portland por la fábrica "La Esperanza" (Cementos Rezola)

\begin{tabular}{|c|c|c|c|}
\hline Años & $\begin{array}{l}\text { Producción } \\
(\mathrm{Tm})\end{array}$ & $\begin{array}{l}\text { Diferencia } \\
\text { respecto al año } \\
\text { anterior }\end{array}$ & $\begin{array}{c}\text { Precio } \\
(\text { ptas } / T m)\end{array}$ \\
\hline 1926 & 50.805 & -2.458 & 96 \\
\hline 1927 & 74.012 & +23.207 & 90 \\
\hline 1928 & 72.150 & -1.862 & 90 \\
\hline 1929 & 92.000 & +19.850 & 90 \\
\hline 1930 & 87.000 & -5.000 & 90 \\
\hline $1931 *$ & $73.368,05$ & $-13.631,95$ & 90 \\
\hline 1932 & 61.714 & $-11.627,05$ & 90 \\
\hline 1933 & 61.355 & -386 & 90 \\
\hline 1934 & 50.733 & -10.622 & 94,5 \\
\hline 1935 & $71.423,24$ & +20.689 .76 & 94,5 \\
\hline
\end{tabular}

* En 1931, la empresa incrementa su capacidad productora de 100.000 a $186.500 \mathrm{Tm}$ anuaIcs, lo cual agudiza la caída de las cifras posteriores. Esta expansión había sido motivada por la importación de $300.000 \mathrm{Tm}$ de cemento en 1929, con las que el gobierno quiso cubrir la posible falta de abastecimiento; recordemos que en aquellas fechas culminaba el programa de obras públicas del Plan Guadalhorce.

Flentes: Estadística(s) Minera(s) y Metaluirgica(s); COIG, "Informe" de 27-IX-32.

32 Gómez Mendoza (1987) lo remonta a 1920. 
revelan una notable recuperación, aunque siguen quedando por debajo de los máximos alcanzados en el Directorio Civil (1926-1929).

La industria de la construcción sufría una marcha descendente desde 1922, año en el que se inició una serie de reales decretos de alquileres que favorecían los intereses de los inquilinos. Fernando de los Ríos, ministro de Justicia, declararía vigentes en 1931 las últimas disposiciones de la monarquía al respecto, por lo que las inversiones en el sector continuaron en un período de aletargamiento. Si en 1923 se habían levantado 51 casas en los principales ensanches de San Sebastián, la cifra fue descendiendo y diez años más tarde no se cedió permiso alguno de construcción ${ }^{33}$. La paralización de la expansión urbana y la ausencia de iniciativas privadas sumieron al sector en una grave crisis que redundó en una fuerte conflictividad laboral.

Las entidades municipales y provinciales acordaron una serie de exenciones fiscales en 1934 para las casas de nueva construcción ${ }^{34}$. Carecemos de datos que nos permitan evaluar sus repercusiones, pero podemos atender al caso vizcaíno, donde se adoptaron idéntidas medidas en 1935. Ricardo Miralles observa para la "provincia hermana" una levísima recuperación, que vuelve a caer bajo mínimos en $1936^{35}$.

El resto de las actividades industriales se realiza en un sinfín de pequeñas fábricas y talleres de muy variada orientación y especialidad: carrocerías, alimentación, construcción de ascensores eléctricos, manufacturas de asta y concha... Las noticias halladas al respecto se refieren a las dificultades que atraviesan, en su mayoría, con motivo de las nuevas y gravosas Bases de Trabajo. Este sería el caso de la construcción de muebles de madera, junco o médula, la manufactura de algunos objetos de lujo - sombrillas y paraguasy el ramo de la alimentación - galletas ${ }^{36}$.

33 Citado por Jaime Brunet en un escrito de la asociación de propictarios de fincas urbanas "Defensa de la Propiedad Urbana en Guipúzcoa", reproducido en COPU, Attas, n. 200.

34 El primer acuerdo, con fecha de 16 de agosto de 1934, fue prorrogado sucesivamente en enero y mayo de 1935 , hasta el 17 de septiembre del mismo.

35 (1988), p. 290.

36 Sector de la madera: el mueble. Las escalas salariales aprobadas por el Comité Paritario Circunstancial el 5 de junio de 1931 (Gaceta de 3 de junio de 1931) fueron posteriormente modificadas por los huelguistas de Rentería y el Comité circunstancial de la madera establecido en aquella villa. Los nuevos salarios igualaban, e incluso llegaban a superar, los pagados en Bilbao. Fue denegada la apelación de los patronos. Alimentación: galletas. El Ministerio aprobó en julio de 1932 las bases de trabajo de 29 de enero del mismo año para el ramo de la panadería y de la galletería en Guipúzcoa, con efectos retroactivos desde diciembre de 1931. Estas imponían la igualdad de salarios femeninos y masculinos, así como un jornal mínimo a las obreras desde los diecinueve años. La COIG afirmó que una empresa bilbaína competidora disfrutaba de la ventaja de 1.000 pesetas diarias en mano de obra gracias a los gravámenes guipuzcoanos. Dos de las tres fábricas de la provincia - Cantabria y Royalta (Hernani) y Galletas Pakers (Rentería) - se vieron abocadas al cierre. Manufactura de para- 
En otros casos, son los efectos de las medidas restrictivas sobre la importación los desencadenantes de una situación que en ocasiones desemboca en el cierre de las factorías ${ }^{37}$.

\section{CONCLUSIONES}

Los indicadores globales de la economía dan a entender que, durante la década de los treinta, España no atravesó una crisis tan profunda ni global como otras economías occidentales. Pero es propio de un modelo de sus características - desarticulado y supeditado a la agricultura - el reducido eco de las actividades comerciales e industriales en el conjunto. Un análisis más desagregado ha revelado a los estudiosos de la economía la existencia de sectores que pasaron por serios problemas. ¿Eran éstos los efectos del panorama internacional? ¿Un caso particular? Ya entre los coetáneos se iniciaría un debate historiográfico que ha llegado hasta nuestros días.

Los temas principales de la discusión han girado en torno al grado de aislamiento de España respecto de los mercados extranjeros y, con ello, el papel desempeñado por el comercio exterior; el protagonismo del Estado, sobre todo a raíz de su política presupuestaria; finalmente, los profesores F. Comín y P. Martín Aceña han reivindicado el sector privado como el verdadero responsable de los ciclos económicos del período de entreguerras $^{38}$. Dejamos así esbozado este debate por ser harto conocido. No obstante, será preciso retomar algunos de sus planteamientos al abordar el presente capítulo.

El estudio del caso guipuzcoano entre 1930 y 1936 nos permite afirmar la existencia de una depresión generalizada. Los datos, tanto los estadísticos como los de naturaleza descriptiva, revelan la actuación de una serie de condicionantes, de variada naturaleza, que propiciaron la recesión de la actividad productiva. Algunos de ellos ofrecen novedades respecto a las explicaciones que se venían apuntando hasta ahora para el caso español, tanto por su naturaleza como por su intensidad. Estas diferencias vendrían marcadas, a nuestro juicio, por los rasgos característicos de los negocios de la provincia: sus reducidas dimensiones - la mayoría se desarrollaba en el marco de la pequeña y mediana empresa- y los estrechos lazos que los

guas y sombrillas: quedó afectada por la elevación de la remuneración de los destajistas. En pocos años, sólo se mantenían cinco fábricas de las ocho anteriormente existentes.

37 La Orden de 28 de abril de 1933 (Gaceta del 5 de mayo) establecía la contingentación de cueros y pieles - vacuno y caballar, de los que España es deficitaria-. La fábrića de curtidos de Hernani se cerró en mayo de 1935 por este motivo, en tanto que otras tropezaron con dificultades de diverso grado para su normal desenvolvimiento.

38 Véase su artículo de 1984. 
unían con algunos mercados extranjeros - Hispanoamérica, Escandinavia, etcétera-. En todo caso, se trata de una de las provincias punteras de la moderna industrialización española, circunstancia que nos lleva a contemplarla como algo más que un mero "caso particulan.

Exponemos a continuación las principales conclusiones del trabajo.

1. Las industrias de material ferroviario, acero moldeado y cemento atravesaron una crisis paralela a las del resto de España. Entre ellas figuran algunas de las principales empresas de la provincia - CAF, San Pedro de Elboibar, Cementos Rezola.

Esta situación es ajena en todo momento a la "crisis universal", tal y como insiste la COIG en 1932. Se relacionaría con la paralizasión de la política de obras públicas que siguió a la caída de Primo de Rivera ${ }^{39}$. El giro presupuestario inferido en 1930 por el ministro de Hacienda, Argüelles, ha sido interpretado como el inicio de una crisis estructural del modelo de crecimiento adoptado a fines del siglo anterior. Este habría sido reforzado durante los años del directorio civil primorriverista.

La desaparición del régimen autoritario y la vuelta a los principios de la ortodoxia presupuestaria iba a sumir aquellos sectores productivos en un serio trance. Los gobiernos republicanos adoptarían una línea continuista en lo referente a todos estos ámbitos, actitud que motivó la persistencia de tan importante coordenada depresiva a lo largo de los años treinta.

2. La coyuntura de reducción de los mercados internacionales jugó un papel muy importante. Las cifras del comercio sufrieron un brutal descenso, paralelo a la escalada de una política intervencionista de tipo regulador. Los sucesivos gobiernos españoles se irían acomodando a la situación con mayor o menor éxito ${ }^{40}$. Su política se concretó, como hemos visto, en la puesta en práctica de toda una serie de controles directos: la restricción del cambio extranjero, la creación del centro de Contratación de Moneda, limitación de ciertas importaciones y exportaciones, registros, contingentes... Su complicada gestión obligó a una burocratización que fue acusada de entorpecimiento adicional para la labor de intercambio ${ }^{1}$.

${ }^{39}$ Reducidos los efectos depresivos del exterior a las zonas de vocación exportadora hortofrutícola, J. L. García Delgado y J. Palafox prefieren hablar de una crisis cstructural del citado modelo de crecimiento.

40 Perpiñá y Grau vinculaba estrechamente la marcha española a la del resto de las cconomías occidentales a través de las relaciones mercantiles. Fuertemente rebatida, entre otros, por J. Palafox, la incidencia del comercio exterior ha sido reivindicada por F. Comín en sus recientes trabajos.

41 Fuera del ámbito estricto del intcrcambio, esta contracción vendría a sumarse a la caída de otras fuentes de divisas - remesas de los emigrantes, turismo, capitales invertidos en el exterior... - La consecuencia inmediata habría sido la de una escasez de medios de 
La producción guipuzcoana establecía un intenso movimiento de exportación de manufacturas e importación de materias primas, todos ellos vitales para la marcha de su economía. Estos vínculos transmitieron pronto a la provincia los efectos de la contracción de los mercados occidentales, marcando decisivamente el desarrollo de muchos de sus sectores. Armas, ferretería, boinas, alpargatas, colofonias y aguartás figuran entre los productos guipuzcoanos de habitual exportación y, por ende, entre los más resentidos por el proteccionismo imperante. Por otro lado, muchos de los procesos de fabricación se verán afectados por las dificultades de abastecimiento regular de sustancias extranjeras vitales. El carbón, la pasta de papel, los aceites de semillas, de tradicional abastecimiento exterior por motivos de calidad y precio, son contingentados o sujetos a fuertes tasas. No es fácil la sustitución por sus equivalentes nacionales, debido a su mayor costo y diferente calidad.

3. Los problemas del sector exterior se combinaron con aquellos que se derivaban de la estructura económica española que legó la Restauración. Esta había consagrado una pluralidad y disparidad regionales de las que se derivaban encontrados conflictos de intereses. La actividad industrial se resintió de estas contradicciones, principalmente en lo referente a las disposiciones que habría de adoptar el gobierno para el fomento del consumo de productos agrarios y mineros españoles.

4. La política laboral y social incidió de manera especial en el ámbito de la pequeña empresa, mayoritaria en el lugar. Los tres primeros meses de la joven República española concentraron la mayor actividad normativa de sus ministerios. Entre ellos figuraba el de Trabajo, detentado por el socialista Francisco Largo Caballero ${ }^{42}$. La acogida deparada a su legislación por parte de la patronal guipuzcoana fue presidida por el temor. Tal actitud venía definida por el cariz socialista del conjunto legislativo, y la limitada capacidad para absorber costes adicionales - tradicionalmente, el incremento de

pago internacionales. Esta se convertiría en un obstáculo enojoso que iba a ralentizar y dificultar el normal desenvolvimiento de las transacciones con el exterior. Entre ot ras mercancías, quedarían afectadas algunas que eran imprescindibles para el normal desenvolvimiento de la economía - véase F. Comín (1987), p. 125-. Los profesores Balcells, Tamames y Ruiz son también partidarios de la vinculación de España con el exterior a través de estos circuitos.

42 Su política de potenciación de las organizaciones obreras, concretamente de la UGT, tuvo como colofón la Ley de constitución de los Jurados Mixtos, en noviembre de 1931. Con su funcionamiento, estos órganos paritarios invertían la relación de fuerzas entre patronos y obreros en la negociación de contratos de trabajo y solución de conflictos, pasando a convertirse en el brazo ejecutivo de la nueva legislación social. En estos años cundió cl temor en los círculos empresariales de todo el Estado. 
la productividad se alcanzaba con el recurso a técnicas intensivas en mano de obra-. Esto la sensibilizaba notablemente respecto a posibles subidas de salarios o de seguros laborables; y fue justamente en estos ámbitos donde operó el primer ministro de Trabajo republicano.

Cabría objetar que el alza salarial beneficia no sólo a los obreros, sino también a las industrias de consumo; pero era ésta una subida que difícilmente podían soportar negocios de las dimensiones de los guipuzcoanos.

"No queremos decir [alega la Liga] que al obrero se le da con exceso lo que a los patronos se les quita sin piedad, sino que para poner en vigor las disposiciones del Ministerio de Trabajo, es indispensable haber solucionado antes el problema económico que nos asfixia, porque no hay que ordenar a los patronos que den, sino ponerlos al mismo tiempo en situación de que puedan hacerlo $(\ldots){ }^{43}$.

Apoyaban esta argumentación en la reducción del número de horas de la jornada, el cierre de algunas fábricas y el aumento del paro que se observa en el transcurso de los años republicanos.

Los pequeños y medianos empresarios veían hundirse su horizonte, ahogados por la conjunción de la legislación laboral con la estrangulación a la que les sometían los contingentes, proteccionismos y falta de divisas. La República les había defraudado porque no supo ofrecer una respuesta a sus peculiares problemas. Amenazaba con llevarlos a la mina; o, lo que es más importante, ellos lo creyeron así.

43 VIP, 190, p. 1, “Del momento. Menos política y más trabajom. 


\section{ABREVIATURAS}

BOG: Boletín Oficial de Guipúzcoa.

CIV: Centro Industrial Vizcaíno.

COCIyNG: Cámara Oficial de Comercio, Industria y Navegación de Guipúzcoa. A partir de 1929 se inició un proceso de separación entre sus departamentos, que culminó en 1931 con la división en los dos organismos independientes que citamos a continuación.

COIG: Cámara Oficial de Industria de Guipúzcoa.

COCyNG: Cámara Oficial de Comercio y Navegación de Guipúzcoa.

COPU: Cámara Oficial de la Propiedad Urbana.

CSCC: Consejo Superior de Cámaras.

D: Decreto.

ED: El Día, diario de San Sebastián.

GE: Guipuizcoa Económica, revista de la COCyNG.

LGP: Liga Guipuzcoana de Productores.

RM: Registro Mercantil.

VIP: Vasconia Industrial y Pesquera, revista quincenal, San Scbastián.

\section{BIBLIOGRAFIA}

CABRERA, Mercedes (1983): La patronal ante la II República: Organizaciones y estrategia (1931 1936).

Castells ARTEChe, Luis (1980): Fueros y Conciertos Económicos: la Liga Foral Autonomista de Guipuzzoa (1904-1906), San Sebastián, Haranburu.

- (1987): Modemización y dinámica política en la sociedad guipuzcoana de la Restauración, 18761915, Servicio Editorial de la UPV, Leioa (Vizcaya).

Castells ARTeChe, luis, y Luengo, Félix (1988): "El proceso de modernización de Guipúzcoa (1876-1920)", Ekonomiaz, 9-10, pp. 255-275.

CatAlán, Jordi (1990): “Capitales modestos y dinamismo industrial: orígenes del sistema de fábrica en los valles guipuzcoanos, 1841-1918m, en J. Nadal y A. Carreras (dirs.), Pautas regionales de la industrialización española (siglos XIX $y$ XX), pp. 125-155.

Comín, Francisco (1987): "La economía española en el período de entreguerras (1919. 1935)", en Nadal, Carreras et al. (comps.), La economia española en el siglo XX. Una perspectiva bistórica, pp. $105-149$

COMín, Francisco, y MARTín ACENa, Pablo (1984): "La política monetaria y fiscal durante la Dictadura y la Segunda República", Papeles de Economía Española, 20, pp. 236-261.

Dirección General de Industria, Ministerio de Industria y Comercio (1935): Estadística de la industria del Papel y Cartón.

Sección de Minas e indústria Metalúrgica, Ministerio de Agricultura, Industria y Comercio (1926-1935): Estadistica(s) Minera(s) y Metalárgica(s) de España.

GÁrate OjANGURen, Montserrat (1976): El proceso de desamollo en Guipuzcoa, San Sebastián, Cámara Oficial de Comercio, Industria y Navegación.

- (1989a): Lección de ingreso de la RSBAP: "La Banca en San Sebastián, 1782-1874", San Sebastián, Suplemento del Boletín de la RSBAP, 2, PP. 25-80.

- (1989b): Comunicación presentada en el "IV Congreso de Historia Económica", Alican. te-Alcoy.

GÓmez MENDOZA, Antonio (1987): "La formación de un cártel en el primer tercio del siglo Xx: la industria del cemento portland", REvisTa DE HISTORIA EcONÓmica, 2. 
HERNÁNDEZ ANDREU, Juan (1979): "Algunos aspectos de la depresión económica estructural española: 1925-1934n, Cuademos Económicos de ICE, 10, pp. 383-400.

Miralles, Ricardo (1988a): El Socialismo vasco durante la II República, Bilbao, Servicio Editorial UPV.

- (1988b): "La crisis económica de los años treinta en el País Vasco", Ekonomiaz, 9-10, Pp. 277-300.

SERrano SANZ, José María (1987): "La política comercial ante la crisis del veintiuno: el primer bienio republicano", III Coloquio de Segovia, pp. 135-151.

Tamames, Ramón (1981): La República. La Era de Franco, Madrid.

Tuñón de Lara, Manuel (1985): El Movimiento obrero en la Historia de España, Sarpe, II. 